\title{
Quoting the Unspoken: An analysis of quotations in spoken discourse
}

\author{
Jessie Sams \\ University of Colorado at Boulder
}

\begin{abstract}
In conversational speech, quotations are often used by speakers to portray events and stories that have happened in the past to their recipients. However, quotations can also be used to communicate thoughts or ideas that have never been spoken aloud before they were quoted. For instance, speakers can quote themselves by quoting inner thoughts that occurred to them during a particular situation; also, speakers can talk about future events and quote material that has never been (and most likely never will be) said in particular situations. This paper explores these types of quotations to find their uses, possible prosodic cues, and recipient participation. ${ }^{1}$
\end{abstract}

\section{Introduction}

In conversational speech, quotations ${ }^{2}$ are often used by speakers to portray events and stories that have happened in the past to their recipients. In the following example, Jemma is reporting to her friend Ivy an incident that had occurred earlier that day (a key to the transcription is included in the appendix).

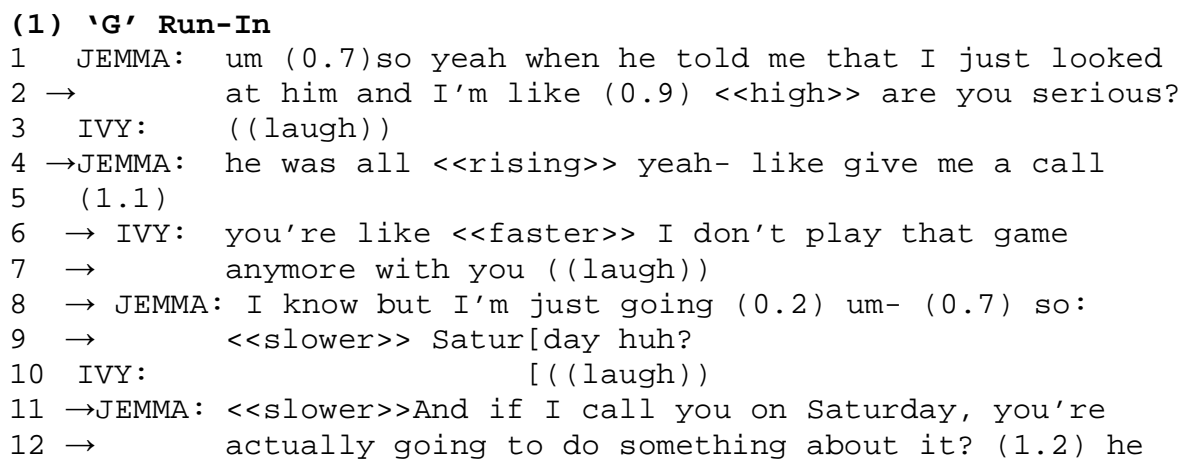

\footnotetext{
${ }^{1}$ I would like to thank everyone who helped me with this paper: Barbara Fox for getting me interested in conversation analysis, Laura Michaelis for suggesting working with spoken quotatives and quotations, and the anonymous reviewers who graciously provided helpful comments for editing the paper. Also, thank you to my family for all their support.

${ }^{2}$ In this paper, all directly reported speech will be referred to as quotations or quoted material. Other researchers refer to this as "direct reported speech" or "DRS" (e.g. Holt 2000, Holt 1996, Niemelä 2005).
}

Colorado Research in Linguistics. June 2007. Vol. 20. Boulder: University of Colorado. (C) 2007 by Jessie Sams. 


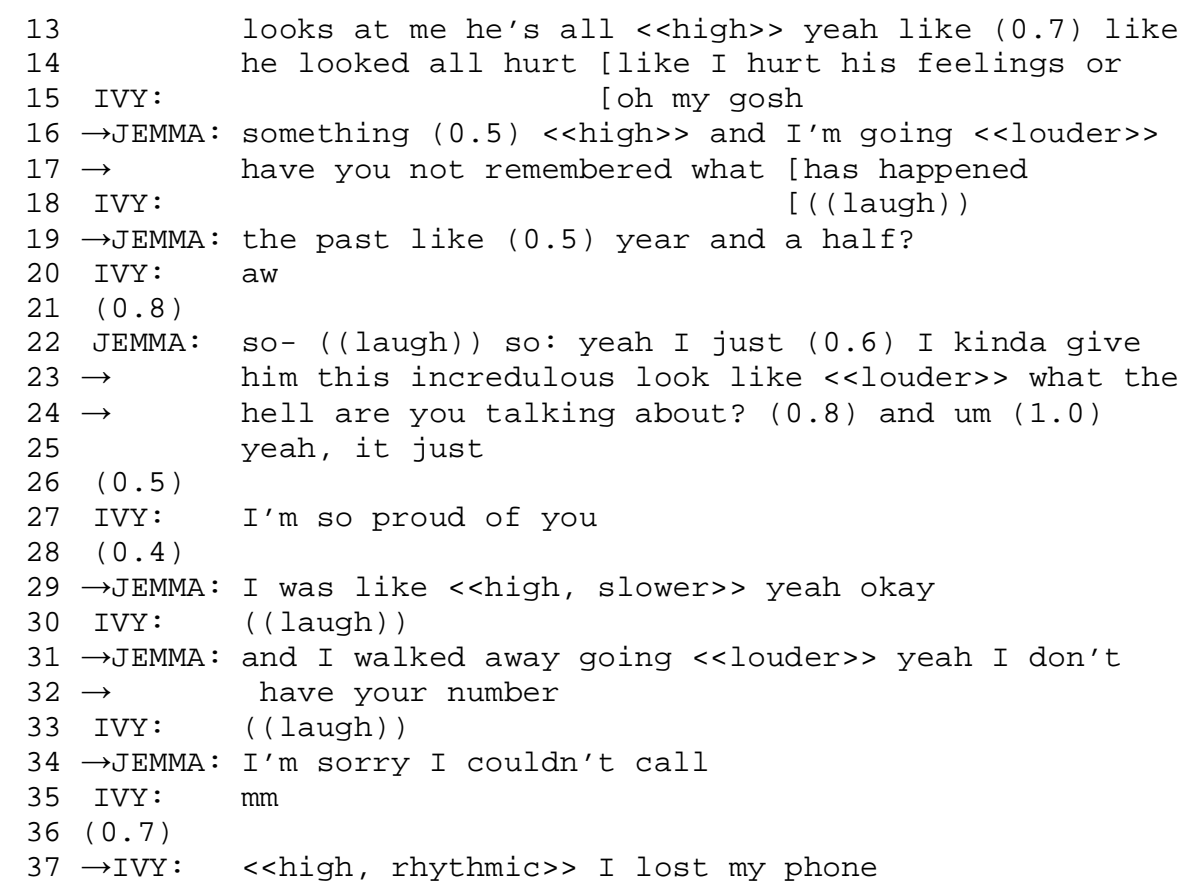

This exchange provides several examples of quotations; two features that distinguish these quotations from indirectly reported speech are the use of the "original's" deixis and the use of a quotative (Holt 1996). For example, in line 2, Jemma uses the pronoun you in the utterance are you serious. It is clear, though, that she is not addressing this question to her recipient, Ivy. Instead, the quoted material shows what she said in the original conversation, and the you refers to the other original participant (who is here simply called ' $G$ '). Therefore, the original deixis remains in the quotation. Also, are you serious is prefaced by the quotative I'm like. While this particular instance utilizes both deixis and a quotative, often quotatives can be deleted.

Jemma is able, through the use of quotations, to not only tell Ivy what happened and what was said but also to provide commentary on the situation. The use of prosodic cues (e.g. louder, high, slower) allows Jemma to include within the quotation how she feels about the reported situation. There has been a great deal of research on the use of quoted speech and affect (Besnier 1993, Clark and Gerrig 1990, Günther 1998, Buttny 1997, Couper-Kuhlen 1998, Holt 1996, Holt 2000). Using quotations allows speakers to have "subtle and intricate ways in which [they] can comment on the utterances they report while simultaneously appearing to simply reproduce them" (Holt 2000).

In reproducing quoted material, though, speakers are not often expected to be providing a verbatim recall of what was originally said. In their paper "Quotations as Demonstrations," Clark and Gerrig (1990) argue that "quotations are a type of demonstration. Just as you can demonstrate a tennis serve, a friend's limp, or the 
movement of a pendulum, so you can demonstrate what a person did in saying something" (764). They state that quotations serve as replications of what the speaker wants to convey to the recipients. In other words, quotations are not exact replicas of what was actually said; rather, quotations demonstrate what another person said, how that person said it, and how the current speaker feels toward what was said. Clark and Gerrig also state that quotations have two functions. The first is detachment: "when [speakers] quote, they take responsibility only for presenting the quoted matter-and then only for the aspects they choose to depict" (792). And the second function is direct experience: "when we hear an event quoted, it is as if we directly experience the depicted aspects of the original event" (793).

The quotations Jemma provides in lines 2, 4, 8-9, 11-12, and 29 fit in well with Clark and Gerrig's idea of demonstrating a previous speech act; however, not all quotations are used strictly for reporting something that was actually said. Some quotations are not used as demonstrations of previous speech acts; for example, in lines 16-17 and 19, Jemma shows how she feels about the situation with ' $G$ ' by saying the quotation have you not remembered what has happened the past like year and $a$ half in a much louder voice than the surrounding material. However, when this is taken into context with the rest of the conversation, it is understood that Jemma did not actually utter these words; instead, this quotation is provided as a demonstration of how she felt during the situation. Therefore, the function of this quotation is different from the earlier examples. It is still quoted material, which can be seen by the deictic use of you and the use of the quotative I'm going; however, it is quoted material that has no original referent. Jemma repeats this type of quotation in lines 23-24, 31-32, and 34.

Ivy, however, uses quotations that are not demonstrations of what she knows to have happened because she has never heard this story before and, therefore, does not know how the story goes. In lines 6-7, Ivy aligns herself with the story by adopting the voice of Jemma in the story by saying I don't play this game anymore with you. Although this quote was never actually spoken by the original participant in the story, Ivy shows she understands the story so far by "chiming in.” Holt (2000), Couper-Kuhlen (1998), Szczepek (2000), and Niemelä (2005) talk about this phenomenon as a way for the recipient to not only show comprehension of the ongoing dialogue but to actually become a part of it and comment on it. Ivy does the same in line 37 when she once again adopts the voice of Jemma and says I lost my phone. In both of these instances, Ivy is using the deictic pronoun $I$ to refer to Jemma-the original participant in the story-and not to herself. By aligning herself with Jemma's stance of the story, Ivy has become an active participant in the story rather than an inactive recipient. 
In some cases, speakers can provide quotations while telling a story even when they were not an original participant. In the following example, Ivy and Mary are talking about a story in the past; although neither of the speakers was actually a participant of the story, Mary uses quoted speech as it was reported to her:

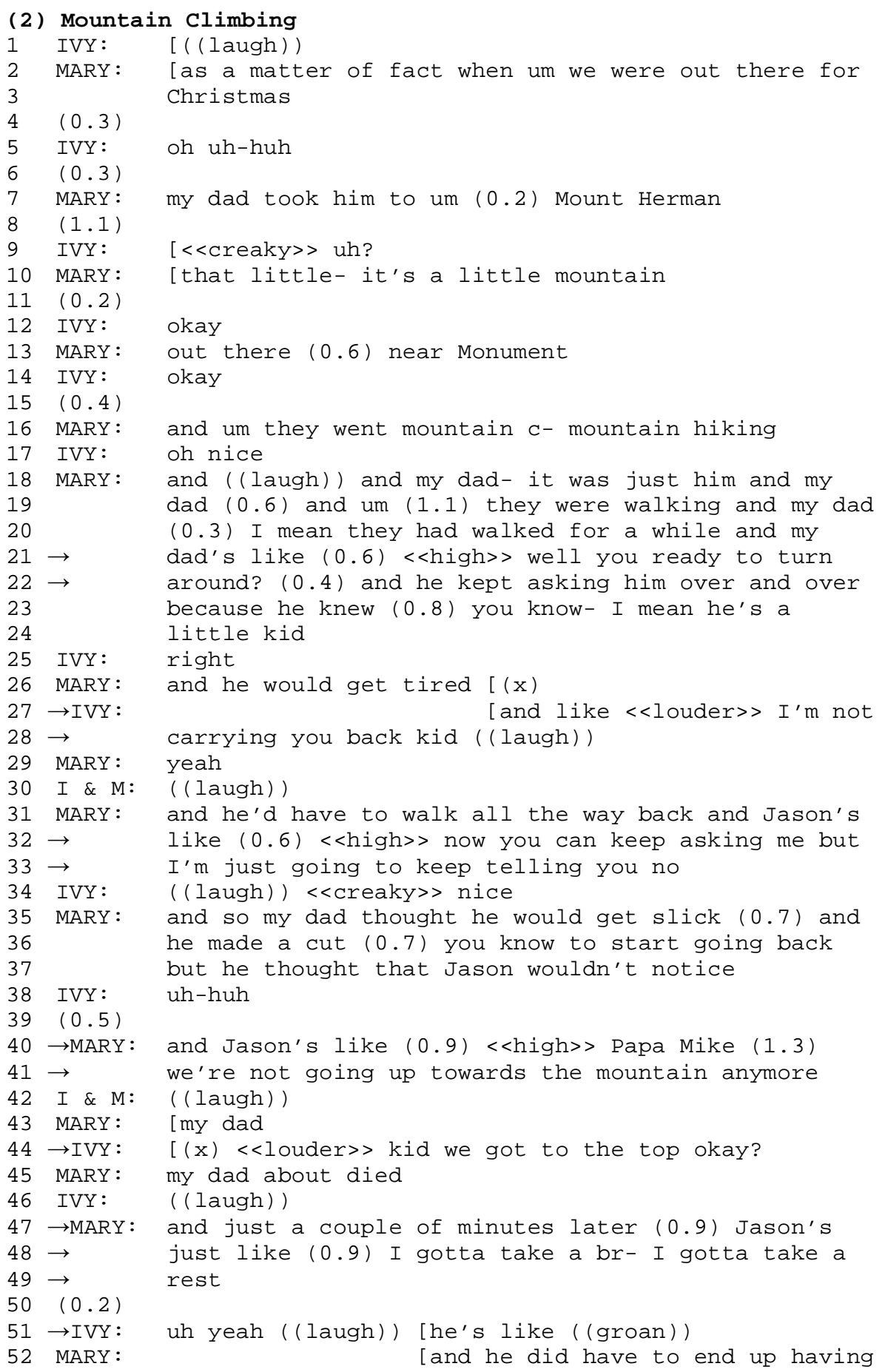


In telling this story, Mary uses quotations to demonstrate what she believed to have happened and to have been said on this mountain hiking expedition; even though she was not personally there, she can tell the story with quotations because she has most likely heard the story from the two participants, her dad and her son. Ivy, though, has never heard this story and again aligns herself with the story by adopting the voice of the dad in lines 27-28 (I'm not carrying you back kid) and line 44 (we got to the top okay?) and the voice of Jason in line 51 with the groaning sound. This example of alignment is different from the previous example because instead of aligning herself with the speaker, Ivy aligns herself with the original participants in the story (neither of which are present for this conversation).

Are these examples of quotations still considered demonstrations even though the speaker is not quoting a known utterance? These types of quotations seem belong to a separate class of quotations, one in which speakers are not demonstrating something they know to have happened; rather, speakers feel free to quote speech that has never been spoken aloud. Based on contextual clues and prosodic information, these quotations can be considered demonstrations of mental states of the speaker (e.g. inner speech) or proposed speech for participants in stories that take place in the future. This paper examines the use of quotations that demonstrate inner speech and future dialogue.

\section{Inner Speech}

Nearly everyone has had the experience of listening to a friend recount a story in the past when she quotes herself as saying something completely out of character. And then the recipient has to ask, "Did you really say that?" Many times, when people tell stories, they include their inner thoughts as reported speech; reporting this unspoken speech gives speakers the chance to "retell" the story so that they can say that witty comeback that they wished they could have actually thought of while the story was taking place. This gives the speaker a chance to put her own spin on the reported dialogue. It also gives her a chance to allow other people to know what she is or was thinking.

In this first dialogue, Ivy is calling Mary for the first time in a while so that they can catch up:

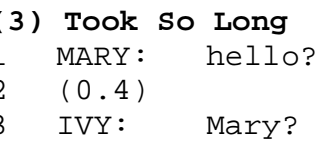




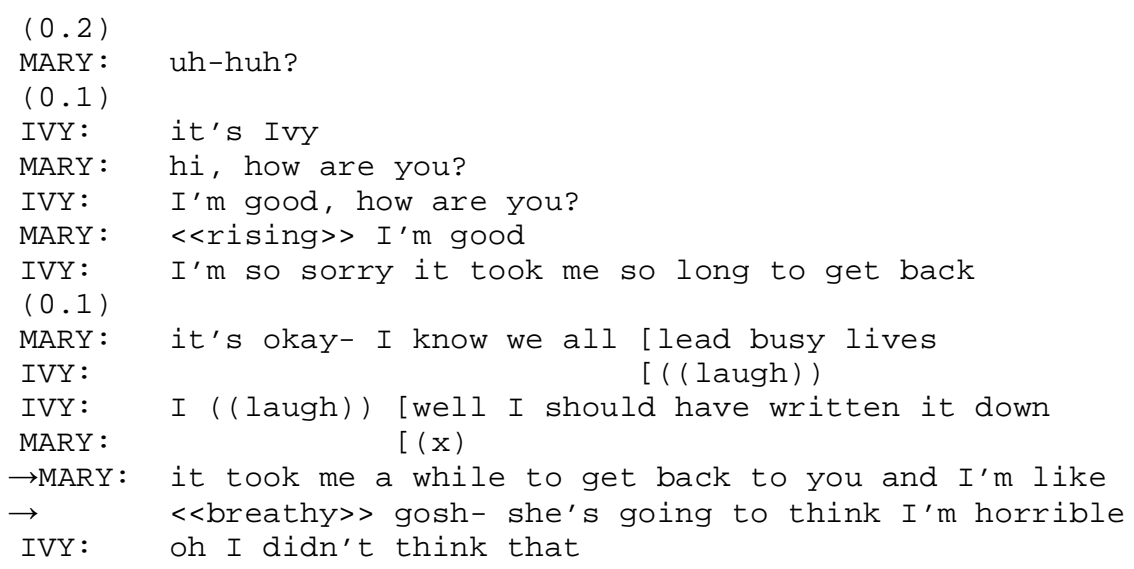

Mary quotes her own inner thoughts in lines $17-18$ by using a quotative (like) and by using breathy speech for the quotation. Here it becomes obvious that this is a quotation and not simply a declaration by Mary's use of the pronoun she; the she Mary is referring to is Ivy, who is her recipient. If Mary wanted to simply say this sentence without quoting it, she would have used the pronoun you since she is addressing her recipient. The breathy quality of her quotation could mean that Mary is portraying that she feels badly for not having called Ivy sooner; therefore, while this could be considered a demonstration of Mary's mental state, it is not a demonstration of a previously spoken quote.

Ivy uses these same methods to quote her inner speech while looking around her parent's house at everything they will have to pack before moving:

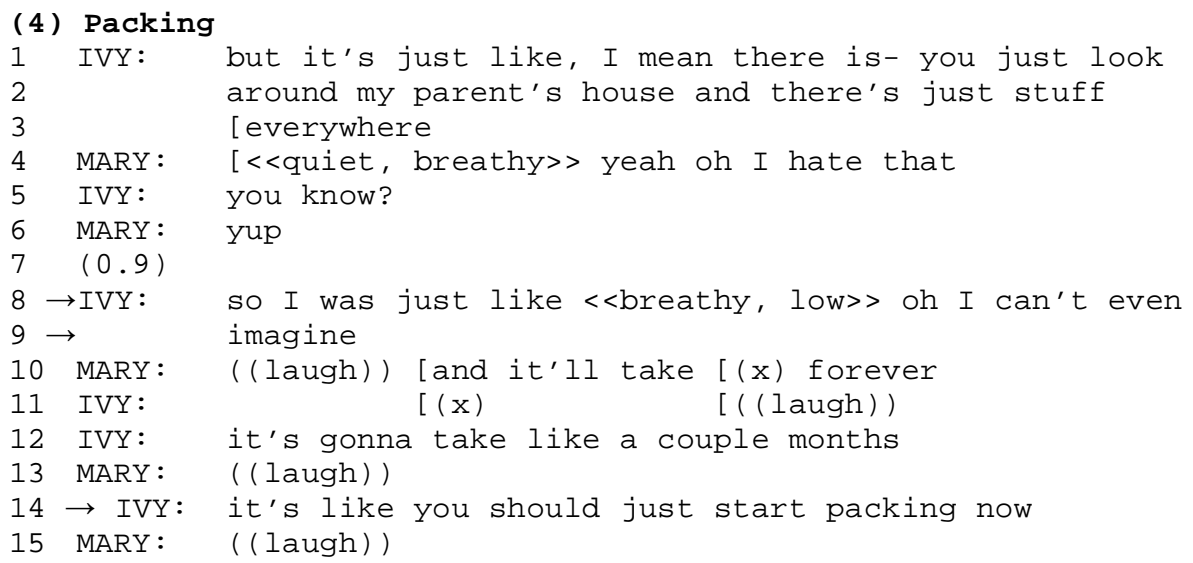

In lines 8-9, Ivy uses a lower pitch and breathy voice to quote her inner speech (oh I can't even imagine) while thinking of the daunting task ahead of her parents; again, this demonstrates Ivy's mental state at the time that the story took place. Along the same lines, in line 14 Ivy again quotes her inner speech (you should just start packing now), but this time her use of normal pitch and the accent on the word now portray a sense of urgency rather than a sense of being overwhelmed. 
One way a speaker can signal that the quoted material is not something that has been stated aloud is the use of the quotative it's like (instead of using I'm like). By the use of it, Ivy is able to signal that she is simply using a quotation to portray her stance towards the situation. Within the quotation, though, she still uses the deictic you to refer to her parents and not to her recipient.

In the next interaction, Ivy and Mary are discussing the gym that Ivy has joined; this example differs from the previous two because Mary uses the same techniques to give voice to what she assumes to be Ivy's inner thoughts in order to become an active participant (line 18).

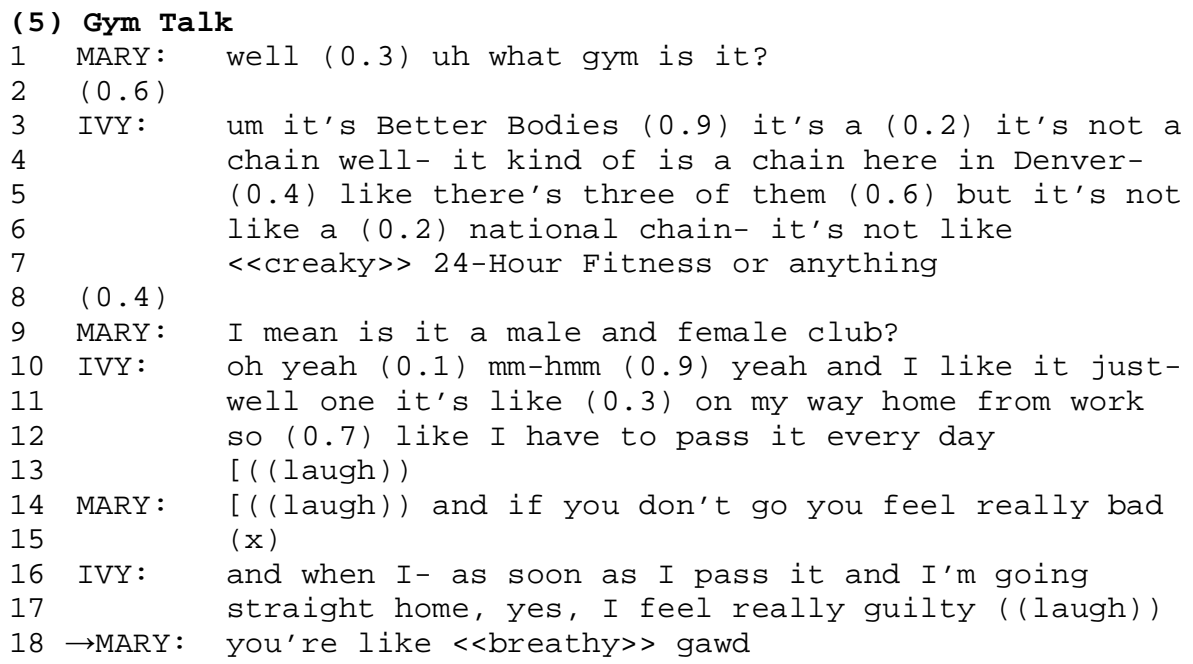

All of these examples show how affect can be portrayed by the use of a quotation even when the quotation is not demonstrating any previously uttered material but is rather demonstrating a thought.

\section{Future Dialogue}

Speakers can also create fictive worlds of dialogue for future situations; because this is dialogue based on speech that has not or probably will not occur, it seems to be a type of "fake" quotation in that the quotations only exist in the world created by the current speakers. Even if the situation being talked about is something that does actually occur in the future, the dialogue that was created to go with it will often times not be a part of that ongoing situation. For example, in the next exchange, Ivy and Mary are talking about their future 10-year high school reunion; this is a reunion that will take place in the future, but the dialogue they propose for this future situation most likely will not: 


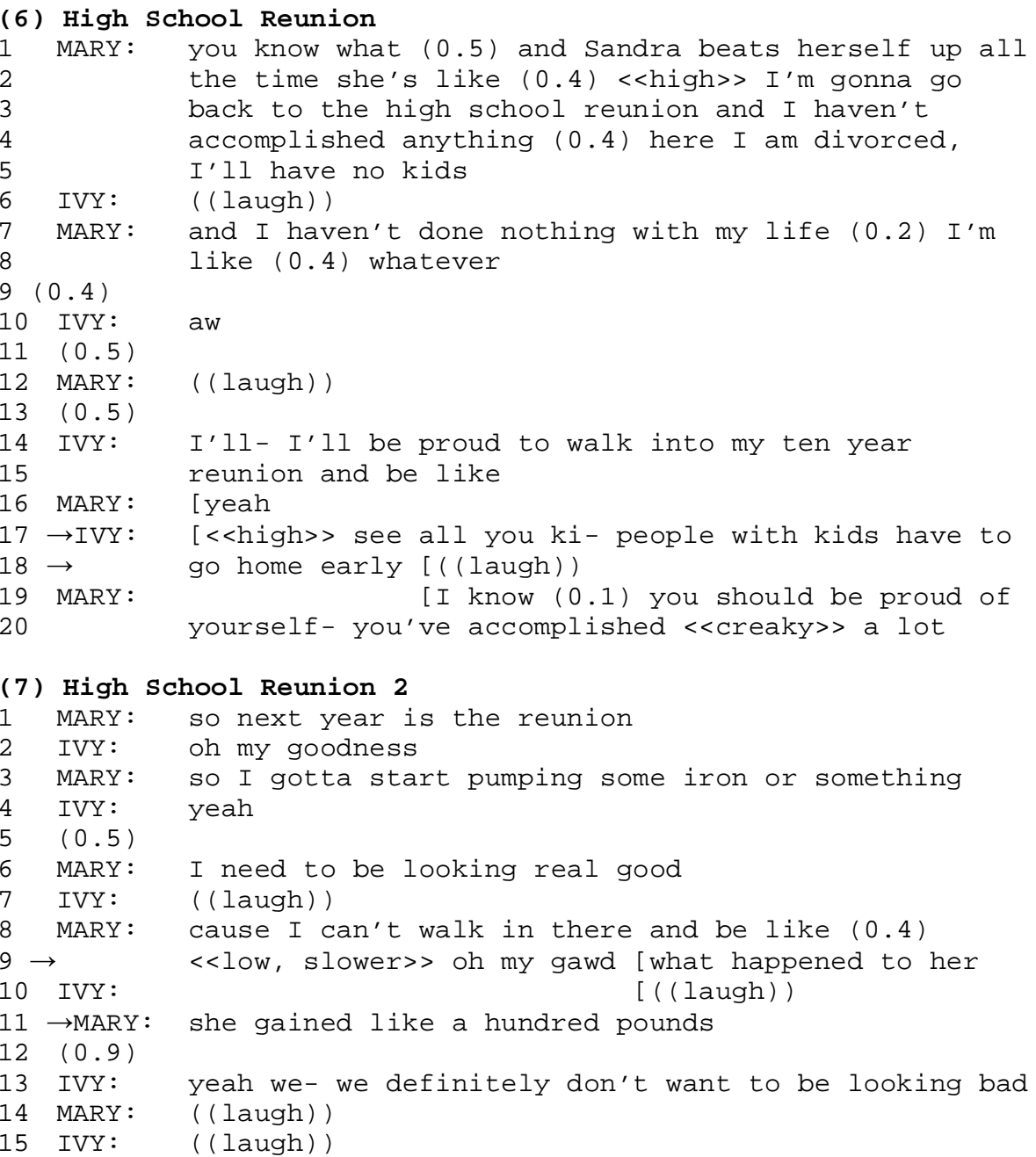

In (6), Ivy creates a quotation of future dialogue for herself for the high school reunion in lines 17-18 (see all you ki- people with kids have to go home early). While the situation may be exactly as she and Mary are describing it (e.g. Ivy may not have any children at the time she attends the reunion), it seems highly unlikely that Ivy will remember to say this exact quote as she is watching the people who have kids at home leave the reunion celebration early. In the same way, Mary creates future dialogue in (7) for her fellow classmates to say or think at the reunion in lines 9 and 11 (oh my gawd what happened to her; she gained like a hundred pounds); these words will most likely not be spoken or thought by anyone at the reunion when Mary arrives.

When speakers create this future dialogue, it is like they are using past experiences to propose hypothetical dialogue for the people involved in a future situation. However, not all future dialogue is based on a situation that will actually occur in the future. The next example is an interaction between Ivy and Jemma. They are 


\section{discussing what they will say should anyone ask them what they did on Super Bowl Sunday; this situation is one that will most likely not take place, so it only exists in the context of this conversation:}

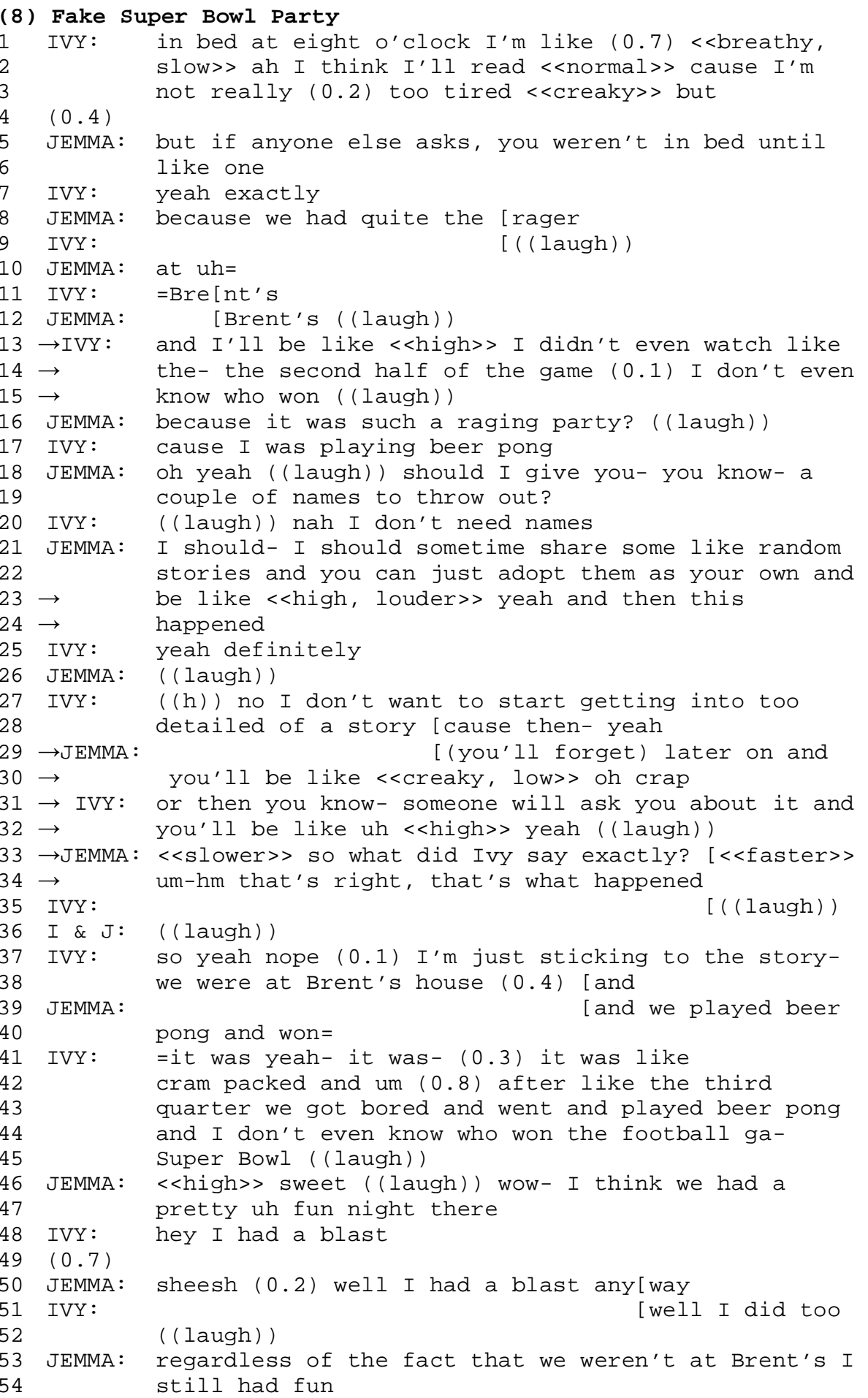


55 IVY: that's right

This interaction has quite a bit of future dialogue that has been created by the two speakers, Ivy and Jemma. In lines 13-15, Ivy creates speech for herself to tell anyone who asks that she did not even see the end of the Super Bowl game because she was having so much fun at the big party (that in reality she did not go to). In the same way, Jemma creates speech for Ivy to say about adopting Jemma's past stories as her own in lines 23-24. These examples, though, seem to act a lot like the examples we looked at in examples (6) and (7) about the high school reunion. Ivy and Jemma appear to be using past knowledge of how they would report being at a party to assume particular stances for similar future situations.

The lines of dialogue that seem the most interesting and different from previous examples are 29-34:

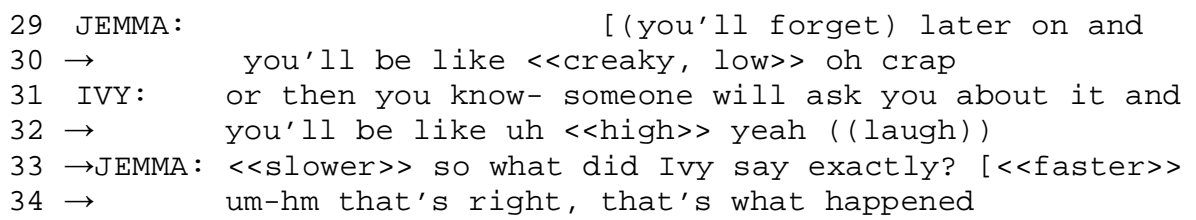

Just before this interaction, Jemma proposed that she could give Ivy stories to tell (previous stories from Brent's parties in the past), but Ivy rejects that idea saying it would get too complicated the more details she wove into her story. That leads directly into the interaction above where Ivy and Jemma go back and forth using quotations to describe why having too many details for their Super Bowl "party" could be dangerous. It is interesting to note that in the interaction, Jemma quotes fictive speech from the 'voice' of Ivy in line 30 (oh crap), and Ivy does the same thing by quoting fictive speech from the 'voice' of Jemma in line 32 (uh yeah). These alone are noteworthy because they have already rejected the idea of adding details to the story, and yet both are quoting speech as if they did add details and then later forgot them. These quotations will never be spoken in this context simply because this context only exists in this conversation.

Lines 33-34 are rather interesting (but difficult to follow if taken out of context). Jemma is doing her own future 'voice' and is quoting what she believes she would say if someone-who knew Ivy and could have heard one version of the story from Ivy-asked Jemma what she did on the night in question. Her response would be to ask "So what did Ivy say exactly?" She would then wait for a response from the interrogator and then reply "Um-hm. That's right. That's what happened." Again, this situation will never take place because a detailed story was rejected by the two girls earlier in the conversation. Are these still demonstrations? They could be construed as demonstrations of hypothetical dialogue for participants involved in 
a fictive situation. Even with this construal, though, it is becoming apparent that saying all quotations are demonstrations of something said, done, or thought is not an entirely true statement; it needs to be modified by saying that some quotations are demonstrations of something said, done in the past. Other quotations can act as demonstrations of proposed hypothetical future dialogue or thought.

Myers (1999) labels this type of quotation as rhetorical reported speech and states that possible functions for this type of speech are to suggest counterarguments and to run a 'thought experiment' in which the participants can play out a rhetorical scenario using quoted material. In lines 29-34 of (8), both of these functions can be seen for the quotations used in the exchange. Ivy and Jemma are discussing why it would be a bad idea for Ivy to randomly adopt stories of Jemma's to share with people, so these lines can be viewed as counterarguments to why they should not do this. Also, because the idea of adopting stories had already been rejected, this can be viewed as a 'thought experiment' because Ivy and Jemma are using quotations to show what could happen should Ivy decide to adopt Jemma's stories.

\section{Prosodic Cues}

Günther (1998) states that prosodic cues are used to achieve certain goals in the context of reported speech:

"(i) to contextualize whether an utterance is anchored in the reporting world or the storyworld; (ii) to animate the quoted characters and to differentiate between the quoted characters; (iii) to signal the speech activities and the affective stance of the reported characters; and (iv) to comment on the reported speech as well as on the quoted characters" (21).

While she has goals for the prosodic cues in reported speech, she does not specify whether these prosodic cues can be generalized to have meaning of their own (e.g. does breathy voice always signify reported inner speech?). Do prosodic cues used for reporting inner speech and future dialogues have patterned uses?

\subsection{Inner Speech}

In analyzing the data, it does not appear to be the case that a specific prosodic cue sets up inner speech; the prosodic cues depend on the mental state portrayed for the inner speech. For instance, the following reported inner speech taken from (1) is portraying a sense of being angry: 


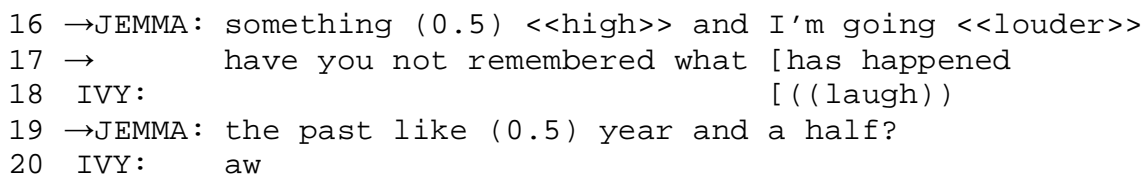

In this interaction, Jemma is using her prosody to portray a sense of being upset with the other original participant in the story by making her voice higher and louder as she speaks. In the next example, though, Ivy uses a breathy, high voice to portray a sense of possibly needing to do something but not necessarily wanting to do that thing right away:

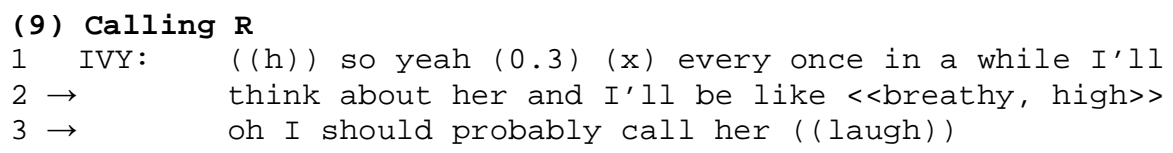

The two examples above both portray the use of a higher voice for the quoted inner speech; although Jemma uses a louder voice to show her anger and Ivy uses a breathy voice to talk about something she should do, the use of a higher voice is present in both. However, not all examples of inner speech use a higher voice pattern:

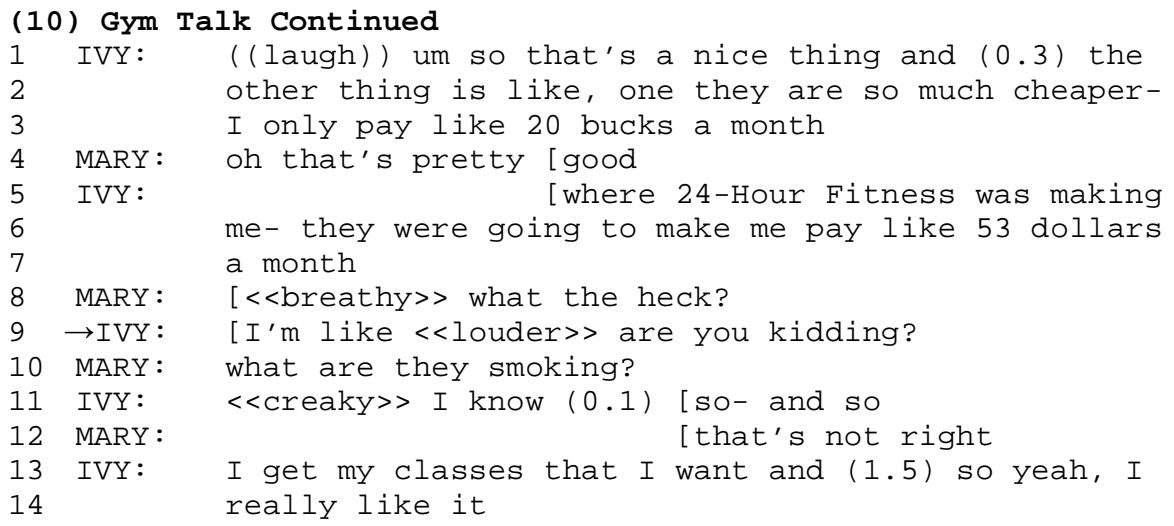

In the above example, Ivy once again voices her inner thoughts through using the like quotative in line 9 (are you kidding) and the deictic pronoun you to refer to the gym and not her recipient; this time, though, her voice becomes louder for the quote to show her indignation at having to pay so much money for a gym membership. In this case, her voice does not become higher when she uses the quotation. As can be seen from the previous three examples, prosodic cues are different for reporting inner speech based on what type of mental state is being portrayed at the time. 


\subsection{Future Speech}

As with reported inner speech, it appears that prosodic cues depend upon the proposed mental state for the future dialogue being conveyed by the speakers. In the following example, Ivy does not change her voice pattern until the middle of the quoted material to portray a sense of wonder surrounding that particular quoted material:

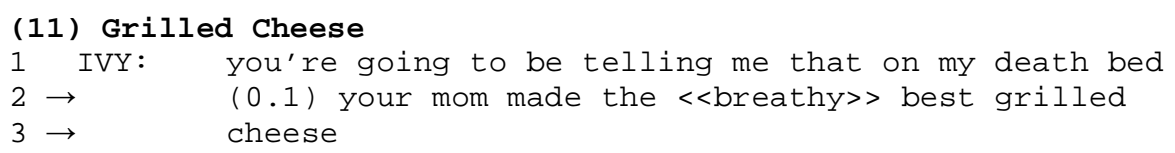

In lines 2-3, Ivy accents the words best grilled cheese by changing her voice pattern to a breathy voice. From the earlier example about the fake Super Bowl party (8), different prosodic cues are used within the same interaction to convey reported future speech:

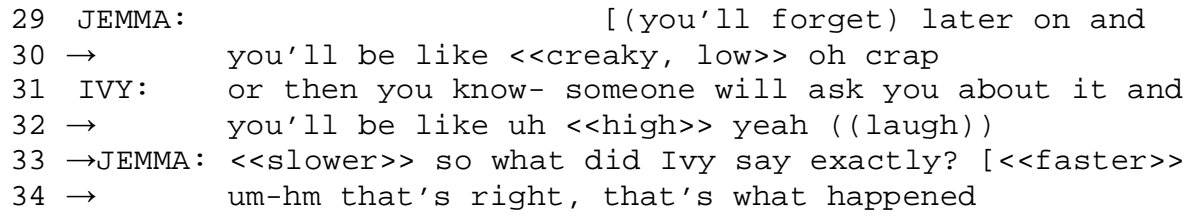

First, Jemma uses a creaky, low-pitched voice in line 30 for the future quotation; but then Ivy uses a high-pitched voice for a future quotation in line 32; right after that, Jemma goes back to using her normal pitch but with a faster and then slower speed for the next chunk of reported future voice (lines 33-34). Therefore, there do not appear to be links between the prosodic cues and the type of quoted material that follows; that information must be gleaned from contextual clues for the recipients to be able to comprehend the unfolding dialogue. Instead of providing prosodic cues to signal what type of quoted speech will follow, these cues provide an insight into the speaker's mental state or into what the speaker assumes is the mental state of a participant. As Myers (1999) stated, "[w]hen the words are not said at all, it is apparently all the more important to convey how they would have been said" (587). Therefore, speakers use prosodic cues as tools for conveying to their recipients how these words could or would have been said instead of as a cue to the onset of a quotation, which is also discussed in Klewitz and Couper-Kuhlen (1999).

\section{Conclusion}


Much of the past research done on quotations in spoken discourse has focused on quotations that quote previously uttered material. However, many quotations in spoken discourse can quote material not spoken aloud in the past or material that is created within the context of a fictitious world. These quotations can still be said to be acting as demonstrations, but they appear to be acting as demonstrations of mental states rather than demonstrations of a particular situation. When using these special quotations, speakers do not appear to be employing specific prosodic cues to make the quote understood; rather, the recipient must rely on contextual cues to fully comprehend the use of the quotation. These quotations that are used to quote the unspoken act like any other quotation used in conversational speech with the use of appropriate deixis, quotatives, and prosody to convey affect; however, their function within conversational speech seems to be in a class of their own.

\section{References}

Besnier, Niko. 1993. "Reported Speech and Affect on Nukulaelae Atoll." In Responsibility and Evidence in Oral Discourse. Jane H. Hill and Judith Irvine (eds.), Studies in the Social and Cultural Foundations of Language, 15: 161181. Cambridge: Cambridge University Press.

Buttny, Richard. 1997. "Reported speech in talking race on campus." Human Communication Research 23: 477-506.

Clark, Herbert H. and Richard J. Gerrig. 1990. "Quotations as Demonstrations." Language 66: 764-805.

Couper-Kuhlen, Elizabeth. 1998. "Coherent Voicing. On Prosody in Conversational Reported Speech." Interaction and Linguistic Structures (InLiSt) No. 1.

Günther, Susanne. 1998. "Polyphony and the 'Layering of Voices' in Reported Dialogues: An Analysis of the Use of Prosodic Devices in Everyday Reported Speech." Interaction and Linguistic Structures (InLiSt) No. 3.

Holt, Elizabeth. 2000. "Reporting and Reacting: Concurrent Responses to Reported Speech." Research on Language and Social Interaction, 33 (4): 425454.

Holt, Elizabeth. 1996. "Reporting on Talk: The Use of Direct Reported Speech in Conversation." Research on Language and Social Interaction 29 (3): 219-245.

Klewitz, Gabriele and Elizabeth Couper-Kuhlen. 1999. "QUOTE - UNQUOTE? The role of prosody in the contextualization of reported speech sequences." Interaction and Linguistic Structures (InLiSt) No. 12.

Myers, Greg. 1999. "Unspoken speech: Hypothetical reported discourse and the rhetoric of everyday talk." Text 19(4): 571-590. 
Niemelä, Maarit. 2005. "Voiced Direct Reported Speech in Conversational Storytelling: Sequential Patterns of Stance Taking." SKY Journal of Linguistics 18: 197-221.

Szczepek, Beatrice. 2001. "Prosodic Orientation in Spoken Interaction." Interaction and Linguistic Structures (InLiSt) No. 27.

Szczepek, Beatrice. 2000. "Formal Aspects of Collaborative Productions in English Conversation.” Interaction and Linguistic Structures (InLiSt) No. 17. 


\section{Appendix: Key to Transcriptions}

\begin{tabular}{|c|c|}
\hline underline & stressed/emphasized by speaker \\
\hline$?$ & rising intonation \\
\hline & falling intonation \\
\hline- & break in sentence (normally used to revise what was just said) \\
\hline & micropause (smaller than 0.1 seconds) \\
\hline$(0.2)$ & length of pause in seconds \\
\hline[ & overlapping speech \\
\hline$=$ & latched speech \\
\hline$(($ laugh $))$ & non-speech sound \\
\hline$<<$ creaky $>>$ & voice quality \\
\hline$(\mathrm{x})$ & transcriber unable to hear the word spoken \\
\hline (word) & transcriber's best guess at what was said \\
\hline$((\mathrm{h}))$ & outbreath \\
\hline
\end{tabular}

